IRA-International Journal of Management \& Social Sciences

ISSN 2455-2267; Vol.06, Issue 01 (2017)

Pg. no. 52-59

Institute of Research Advances

http://research-advances.org/index.php/RAJMSS

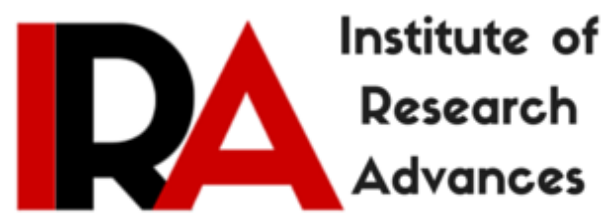

\title{
Disaster Profile of India: A Theoretical Understanding of Regional and Seasonal Perspective
}

Prof. (Dr). Shabir A. Bhat

Professor, The Business School,

University of Kashmir, Hazratbal, Srinagar Kashmir-190006, India.

Dr. Qurat-ul-Ain Shah

Consultant, Centre for Rural Development \& Panchayti Raj

Institute of Management, Public Administration \& Rural Development,

Srinagar, India.

Type of Review: Peer Reviewed.

DOI: http://dx.doi.org/10.21013/jmss.v6.n1.p8

\section{How to cite this paper:}

Bhat, S., \& Shah, Q. (2017). Disaster Profile of India: A Theoretical Understanding of Regional and Seasonal Perspective. IRA-International Journal of Management \& Social Sciences (ISSN 2455-2267), 6(1), 52-59. doi:http://dx.doi.org/10.21013/jmss.v6.n1.p8

(C) Institute of Research Advances

\section{(cc) EY-NC}

This work is licensed under a Creative Commons Attribution-Non Commercial 4.0 International License subject to proper citation to the publication source of the work.

Disclaimer: The scholarly papers as reviewed and published by the Institute of Research Advances (IRA) are the views and opinions of their respective authors and are not the views or opinions of the IRA. The IRA disclaims of any harm or loss caused due to the published content to any party. 


\section{ABSTRACT}

India's unique geo-climatic position makes India particularly vulnerable to natural disasters. The regional and seasonal profile of India has been presented in this paper. The main objective of this paper is to illustrate and explain the basic understanding of various natural disasters happening in various parts of India. In this paper regional profile of India is taken into consideration wherein stress has been given on various disasters happening all over the country as per geographical location of the area. Author also explains seasonal profile of India in which focus is given on the various seasons and disasters associated with each seasonal cycle.

Key-Words: Natural disasters, seasonal profile, Regions, etc

\section{INTRODUCTION}

Disasters are sudden and intense events which result in considerable destruction, injuries \& deaths, disrupting normal life as well as the process of development. Increasing population and various other socio-economic factors have forced people to live in vulnerable areas. Disasters are perceived to be on the increase in terms of their magnitude, frequency, and economic impact. Unique geo-climatic conditions make the Indian region particularly vulnerable to disasters. Floods and high winds account for around 60 percent of all disasters. About 54 percent of the sub-continent's landmass is vulnerable to earthquakes, while about 4 crore hectares, that is, about 12 percent of the country is vulnerable to periodic floods. New disaster threats have also developed, such as the tsunami disaster of December 2004 which was an unprecedented natural disaster. The total expenditure on relief and reconstruction in Gujarat alone after the severe earthquake of January 2001 has been about Rs. 11,500 crore in that year. Thus it is evident from the facts and figures that for the national development and citizen's welfare, development process needs to be sensitive towards disaster prevention and mitigation aspects. There is an urgent need to look at the disasters from a development perspective. In this context, certain five year plans have been framed to plan for disaster preparedness and mitigation, in order that periodic shocks to our development efforts are minimized. In order to implement these plans, India has integral administrative machinery at national, State, District and sub-district levels. The basic responsibility of undertaking rescue, relief and rehabilitation measures in the event of disasters is that of the concerned state Government. In this situation, the Central Government supplements the efforts of the states by providing necessary financial and logistic support. The ministry of Home Affairs is the Nodal Ministry for coordination of relief \& response, and overall disaster management of natural disasters. In addition, the department of Agriculture \& Cooperation is the Nodal Ministry especially for drought management, and the Geological Survey of India is the Nodal agency for landslide management.

For an effective disaster management and capacity building, joint efforts and active participation of political leaders, administrators and citizens is imperative. Important function of the non-governmental organisations and community based organisations is that of linkage between Government \& the community. It is important that this link is maintained effectively at all the three stages of disaster management viz. pre-disaster, during disaster and post-disaster stage. This function is rendered through different mechanisms as per the requirements of a situation, such as distribution of relief material, ensuring sanitation \& hygiene, and damage assessment. Media plays equally important role in disaster management as it can reach millions of people in short time.

\section{NATURE OF NATURAL DISASTERS}

A natural disaster could occur due to an immediate extreme event or it could be the result of a long duration process, which disrupts normal human life in its established social, traditional and economic system to a considerable extent. The United Nations define it as "the occurrence of a sudden or major misfortune which disrupts the basic fabric and normal functioning of a society (or community)." The term 
'Disaster' is commonly used to denote any extreme event, be it natural man-made, which brings about loss of life, property, infrastructure, essential service and means of livelihood to an extent that it becomes difficult to cope with the situation due to being beyond the normal capacity of the affected communities to deal with unaided. A hazardous situation turns into a disaster event when the affected community (or district or state or country) needs immediate and prolonged assistance and support to deal with the situation and its aftereffects.

Disaster is the culmination of a hazard in a situation where the impact is accentuated by the vulnerability of the community. To be more specific, a hazard may be regarded as a pre-disaster situation, in which some risk of disaster exists. In fact, hazards can be posed both by natural phenomena and by man-made events. Therefore, disasters can be natural or man-made.

The severity of a disaster is assessed on the basis of disruption to normal pattern of life, impacts like loss of life and property, injury, hardship and adverse effects on health; community needs; specially shelter, food, clothing, medical assistance and social care; damage to infrastructure, buildings, communications; and the requirements of rehabilitation.

\section{NATURAL DISASTERS IN INDIA}

India's unique geo-climatic position makes India particularly vulnerable to natural disasters. India is a vast peninsula of sub-continental size and surrounded by sea on three sides and has the Himalayas range on the fourth side, which has some of the tallest mountains of the world. That is why India has to face a very large variety of disastrous events of geological, oceanic or climatic origin. There is a broad classification of natural disasters in India. Brief description is mentioned below as per the geological origin of these disasters.

\subsection{EARTHQUAKE}

A sudden geological event below the surface of the earth results in generation of waves that travel far and wide and cause vertical and horizontal vibrations. The consequential motion causes destruction.

The severity of the impact depends on the magnitude of earthquake, which in turn depends on the amount of energy released at the spot where the geological event took place below the surface of the earth. Earthquakes occur suddenly, and thus there is no dependable technique for prediction of earthquakes as yet. India is highly vulnerable to earthquakes and severe earthquakes have occurred here.

\subsection{VOLCANIC ERUPTION}

Volcano can be described as a vent or chimney, to the earth's surface, from a reservoir of molten rock, called magma, deep in the crust of the earth. It is not that volcanoes are always emitting lava, steam, or smoke. Many volcanoes have been "sleeping" for decades or even longer. In the context of forecasting of volcanic eruptions, it can be stated that short-term forecasts within hours or days may be made through volcano monitoring techniques. There are only two volcanoes in the Indian Territory i.e. Narcondam and Barren Islands-both in Andamans. Both the volcanoes are "sleeping" volcanoes' although the Barren Island volcano emits some heat and smoke occasionally and goes to sleep again. India is not much affected due to the volcanoes compared to the other countries like Italy, Mexico, Indonesia and Iceland.

\subsection{LANDSLIDES}

Landslides are defined as the mass movement of rock debris or mud down a slope and have come to include a broad range of motions, whereby falling, sliding and flowing under the influence of gravity dislodged earth material. They also occur as secondary effects of heavy rainstorms, earthquakes and 
volcanic eruptions. Landslides occur as a consequence of changes, either sudden or gradual, in the composition and structure of rocks or vibrations in the earth's surface.

Landslide can be caused by poor ground conditions, geomorphic phenomena, heavy rainfall, earthquakes or undercutting of the base of slopes by rivers and quite often due to heavy spells of rainfall coupled with impeded drainage. They are common in mountainous areas, such as Himalayas and the Western Ghats where they frequently destroy the infrastructure, agriculture and dwellings, resulting in considerable loss of life and property besides blocking vital needs in the inaccessible areas.

\subsection{SNOW AVALANCHE}

An avalanche is defined as the event in which a large mass of snow, ice, rock or other material moves swiftly down a mountain side or over a precipice and crushes everything in its path. An avalanche starts when the large mass of snow, ice and rock overcomes the frictional resistance of the sloping surface, either due to rain, melting of ice base or vibrations of any kind.

It will be seen that landslides and avalanche are events of mountain regions and are rather similar in nature and impact. The basic difference is that landslide involves movement of rock, soil and mud whereas avalanche comprises, snow, ice and rock. Landslides can occur in smaller hills or rocky slopes but avalanches occur in high mountains with snow in abundance.

\subsection{TSUNAMI}

Tsunami is a Japanese term for sea waves generated by undersea earthquakes. These waves may originate from undersea or coastal seismic activity, or volcanic eruption. Sea water is displaced into a violent and sudden motion ultimately breaking over land even at very long distances with great destructive power. It is to be noted that while the coasts are hit by very high waves of water, there is hardly any appreciable wave on the high seas. Therefore, ships on the high seas are not affected.

In most cases, tsunami could be the after-effect of undersea earthquake due to which the abrupt vertical movement of ocean floor generates waves, which travel at high speed in the ocean. As they approach land, their speed decreases while their height increases. It can be highly destructive to coastal areas as was witnessed during then catastrophic tsunami event in December 2004.

\subsection{CYCLONE}

Tropical cyclones are characterized by destructive winds and copious rainfall, which causes flooding. In such storms, winds can exceed speeds of over $120 \mathrm{kmph}$. Due to such strong wind forcing, sea-water accumulates ahead of the cyclone as it moves towards the coast. When a cyclone hits the coast, the accumulated enormous mass of sea-water strikes the coast as a giant sea wave called storm surge which can have heights of the order of tens of metres. The storm surge with torrential rains and very strong winds brings widespread devastation to coastlines and islands lying in their paths. Cyclones pose a major threat to life and property. These storms are called cyclones in India. In other parts of the world they have different nomenclature, like hurricanes in America and typhoons in Japan.

In India, there are two cyclone seasons viz. Pre-monsoon (April \& may) and Post-monsoon (October \&November). More cyclones form in the Bay of Bengal than in the Arabian Sea.

\subsection{FLOOD}

Flood denotes inundation or accumulation of water. In other words, it results from an imbalance between inflow and outflow of water. Floods can occur through heavy rains, dam failure, rapid snow melts, river 
blockages or even bursting of water rains. Floods result in damage, deaths and injuries, and create problems in drinking water supply and food shortage.

There are three types of floods i.e. flash floods, river floods, and coastal floods. Flash floods are generally events of hill areas where sudden very heavy rain over a limited area can cause string flow. River floods occur due to heavy inflow of water from heavy rainfall, snowmelt, and short intense storms. Flooding in rivers is also caused by inadequate capacity within the banks of the river to contain high flows, river banks erosion and silting of riverbeds, synchronization of flood in main and tributary rivers, and flow retardation due to tidal and backwater effects. Coastal floods are caused due to tsunami or heavy rainfall from cyclones and the storm surge associated with a cyclone.

\subsection{DROUGHT}

Drought is a temporary reduction in water availability on an area for unusually long period. Depending on the resulting water scarcity, a drought has disastrous and long-term socio-economic impacts, which may last for months and in some cases years. It is a slow phenomenon. It is generally caused by adverse water balance, or scarcity of water to satisfy the normal needs of agriculture, livestock or human population. There are three types of droughts i.e. meteorological drought, hydrological drought, agricultural drought. Meteorological drought occurs when the monthly or seasonal rainfall over an area is appreciably below normal. Hydrological drought occurs when the water scarcity over an area results in reduction in the available water in surface water bodies and the water table also recedes. Agricultural drought occurs when the water scarcity results in partial or total loss of crops and affects agricultural activity adversely.

\subsection{HEAT WAVE AND COLD WAVE}

These are spells of extreme surface air temperature over a region for rather prolonged periods of several days for few weeks. When the maximum temperature in the day over an area overshoots in the hot weather months (March to June), it leads to heat wave. Similarly, when the minimum temperature falls appreciably below normal in the winter months, it is called cold wave.

\subsection{GLOBAL WARMING}

Increase in greenhouse gases (carbon dioxide, methane, nitrous oxide and others) retards cooling of the earth's surface at nights and this tends to increase the minimum temperature i.e. morning temperature, almost all over the globe resulting in the phenomenon called Global Warming. There would not only be less cooling of the earth's surface at night but the atmosphere will also get warmer due to trapping of the heat on account of green house effect.

\subsection{SEA LEVEL RISE}

Any increase in the average temperature of the earth is bound to have two impacts. Firstly, the glaciers, permafrost, ice caps on the poles and mountain peaks will witness increased melting and consequent increase in the waters in rivers and oceans. Secondly, the large body of water in the seas will expand in volume due to increased temperature. Both these factors will create a rise in the level of water in the seas and oceans, which eventually poses serious problems to the inhabitants of coastal and island areas and affects their socio-economic wellbeing.

\subsection{OZONE DEPLETION}

Ozone is an isotope of oxygen which is created in the lower stratosphere where under conditions of low atmospheric pressure, the ultraviolet radiation in the sun's rays breaks the oxygen molecule into atomic oxygen, which combines with oxygen molecule to form ozone. The ultraviolet radiation breaks up the ozone molecule into a normal oxygen molecule and atomic oxygen. Thus the process goes on and creates 
a layer of ozone in the upper atmosphere with maximum density of ozone around $20 \mathrm{~km}$ or so above the earth. This process consumes a large part of harmful ultraviolet radiation in the sun's rays and thus saves human, animal and plant life on the earth from the harmful effects of ultraviolet radiations. Certain chemicals in use on earth send chlorine up in the upper atmosphere where under certain conditions of low temperature and darkness, chlorine consumes atomic oxygen in a chemical reaction with the result that ozone formation is reduced thus lowering the ozone density in the ozone layer in upper atmosphere. This process of ozone depletion ensures that less amount of ultraviolet radiation in the sun's rays gets consumed in the ozone layer and more ultraviolet radiation reaches the earth's surface to create harm.

\section{REGIONAL DISASTER PROFILE OF INDIA}

North India comprising the Himalayan mountainous region and the Indo-Gangetic plains ahs highly variable topography with some of the tallest mountains and perennial rivers. Its northern most boundary also happens to be the zone of collision of two major tectonic plates, viz. the Indian plate and the Asian plate. The area also has many geological faults. North India is also characterized by spells of hot, cold and rainy weather and attributes can vary within wide limits creating unusual situations. As a result of these characteristics geographical, climatic, and geological features, North Indian states (J\&K, HP, Punjab, Haryana, Uttaranchal, Delhi, UP, Bihar) are visited by natural disasters in the form of earthquakes, landslides, avalanches, floods, droughts, heat and cold waves.

The location and climate of East and North East India (WB, Sikkim, Assam, Arunachal Pradesh, Nagal and Manipur, Meghalaya, Tripura, Mizoram) are such that these states are visited by earthquakes, landslides, floods, and droughts. West Bengal can be affected by cyclones also.

The central parts of the country (Orissa, Chhattisgarh, Jharkhand, M.P, Rajasthan, Gujarat, Maharashtra and Goa) have a highly variable rainfall regime, both in time and space. Therefore, floods and droughts are major disasters in the area. Orissa and Gujarat suffer heavily from cyclones. Goa and Maharashtra suffer from very heavy rain fury. Orissa has also suffered from heat waves in recent years.

The peninsular India (Andhra Pradesh, Karnataka, Tamil Nadu, and Kerala) suffer mainly from cyclones, floods and droughts. While Kerala escapes the fury of cyclones, it suffers from earthquakes and landslides in addition to floods and droughts. The Telangana and Rayalaseema area of Andhra Pradesh are highly rain-deficient areas and therefore suffer drought conditions often.

Among the Island groups, Andaman \& Nicobar Islands are vulnerable to earthquakes, heavy rains and occasionally cyclones. Andaman Islands also have two sleeping volcanoes i.e. Narcondam and Barren Island (as already discussed in this paper).

The Lakshadweep Islands are coral islands and therefore are only a few centimeters above the sea level. They could be threatened in case of significant sea level rise due to the global warming. This could threaten some of the India's biggest cities like Kolkata, Chennai and Mumbai, which are commercial hubs.

\section{SEASONAL DISASTER PROFILE OF INDIA}

India experiences four distinct seasons form climatic point of view. These are:

- Winter season (December, January \& February)

- Pre-monsoon or Hot weather season (March, April and May)

- Monsoon season (June to September)

- Post-monsoon season (October, November) 


\subsection{Winter season (December, January \& February)}

During these months, Himalayan range receive copious amounts of rain and snow and the weather phenomenon known as "western disturbances" also brings in strong winds with rain, which at time can be heavy. Hence, the mountainous areas of north India are prone to snow avalanches and landslides. In the aftermath of rainy spells in this cold season, one or two spells of cold waves occur usually. Heavy fog creates aviation hazard, and hail damages crops and orchards in the plains of north India.

\subsection{Pre-monsoon or Hot weather season (March, April and May)}

Cyclones take shape over the Bay of Bengal and the Arabian Sea and move westward or northwestward. Thus the eastern coast is more vulnerable to cyclones and accompanying storm surges. The cyclones that generate in the Arabian Sea move west or northwestwards, thus sparing the west coast but pose serious risk to the oil exploration outfits in the Arabian Sea. If a cyclone recurves, it affects Gujarat adversely and gives considerable rains in Rajasthan as well and creates floods sometimes.

\subsection{Monsoon season (June to September)}

T his is the flood season for the entire country and floods occur wherever monsoon becomes more active. Conversely, the areas where the monsoon remains weak, suffer from drought in this season. Landslides are a common feature in the hilly areas of Himalayas from J\&K to the northeastern States. Landslides also occur in the Western Ghats and in the hilly areas of Kerala in this season.

\subsection{Post-monsoon season (October, November)}

This is again a cyclone season when cyclones generate in the Bay of Bengal and Arabian Sea and move west or northeastwards in the same general fashion as in the pre-monsoon season. But the cyclonic activity is usually more pronounced in this post monsoon season as compared to that in the pre-monsoon season. This is also the season when the southern states of Andhra Pradesh, Karnataka, Tamil Nadu, and Kerala receive considerable rainfall from the northeast monsoon, and are therefore vulnerable to the threat of floods.

\section{CONCLUSION}

Disasters are sudden and intense events which result in considerable destruction, injuries \& deaths, disrupting normal life as well as the process of development. Disasters are perceived to be on the increase in terms of their magnitude, frequency, and economic impact in India. It has been emphasized that a disaster retards the development process in the affected area and extends to the neighbouring regions also. Various types of natural disasters that occur in India like Earthquakes, Volcanic eruption, Landslides, Snow Avalanches, Tsunami, Cyclone, Floods, Drought, heat \& cold Waves, sea Level Rise, Gl0bal warming, Ozone depletion have been described very briefly and the regional and seasonal profile of their occurrence have been outlined. Seasonal profile briefly describes four different seasons of India like Winter season covering December, January \& February; Pre-monsoon or Hot weather season which include March, April and May; Monsoon season that lasts from June to September; and finally Postmonsoon season covering October \& November.

\section{REFERENCES}

1. Bhat Shabir, Shah Qurat, 2015, "An Integrated Disaster management Model for Admin", International Journal in Commerce, IT \& Social Science, 2394-5702.

2. Bhat Shabir, Shah Qurat, 2016, "Disaster management in Jammu \& Kashmir", International Journal in Management \& Social Science, 2321-1784. 
3. Government of India, Ministry of Home Affairs, NDM Division, Disaster Management in India: A Status Report, New Delhi.

4. Oliver, John E. (Ed), 2005, Encyclopedia of World Climatology, Springer, Netherland.

5. Sinha, D.K., 2006, Towards Basics of Natural Disaster reduction, Researchco. Book Centre, New Delhi.

6. Singh, Tej, 2006, Disaster Management Approaches and Strategies, Akanksha Publishing House, new Delhi.

7. Thomas, Babu, 1993, Disaster response: A handbook for emergencies, CASA, New Delhi. 